\title{
Is Any Job Better than No Job? Life Satisfaction and Re-employment
}

\author{
Carola Grün • Wolfgang Hauser • Thomas Rhein
}

Published online: 10 July 2010

(C) The Author(s) 2010. This article is published with open access at Springerlink.com

\begin{abstract}
Using data for West Germany from the German Socio-Economic Panel, we analyse the impact of transitions from unemployment to full-time employment on life satisfaction, with special focus on the influence of job quality. We apply various indicators of job quality (self-reported job satisfaction, wages, type of contract, and indicators of the fit between the worker and job requirements). We control for the influence of income changes and other factors affecting life satisfaction, using a conditional logit estimator. Results suggest that job quality only matters to some extent, and often people in bad jobs are still better off than those who remain unemployed. This effect is statistically significant for most indicators of job quality, except for workers with low job satisfaction and for those whose new job is much worse than their pre-unemployment job.
\end{abstract}

We would like to thank Gesine Stephan, conference participants at the ISQOLS conference 2007 in San Diego, USA and the 2008 meeting of the IARIW in Portoroz, Slovenia, as well as seminar participants in Nuremberg, Göttingen and Vienna and three anonymous referees for valuable comments and suggestions on earlier versions. All remaining errors are ours.

\section{Grün $(\bowtie)$}

Faculty of Economic Sciences, Göttingen University,

Platz der Göttinger Sieben 3,

37073 Göttingen, Germany

e-mail: cgruen1@gwdg.de

W. Hauser

ZIRN - Interdisciplinary Research Unit on Risk Governance

and Sustainable Technology Development,

University of Stuttgart, Stuttgart, Germany

T. Rhein

Institute for Employment Research (IAB),

Nuremberg, Germany 
Keywords Unemployment $\cdot$ Re-employment $\cdot$ Job quality $\cdot$ Life satisfaction

JEL Classification I31 · J28

\section{Introduction}

There is well-established evidence that unemployment has a strong negative impact on life satisfaction. This has been shown in cross-sectional comparisons of satisfaction levels between employed and unemployed persons (Clark and Oswald 1994). The evidence has been confirmed by longitudinal studies that follow the same individuals over time (Winkelmann and Winkelmann 1998; Kassenboehmer and Haisken-DeNew 2009), thus avoiding problems of interpersonal comparability of subjective well-being, inherent in cross-sectional studies. Persons who lose their job report, on average, a sharp drop in life satisfaction, which seems to be caused only to a minor degree by income losses. This drop in life satisfaction can be conceived as the psychological cost of unemployment. There are also a lot of psychological case studies with the same conclusion (for a review of this literature, see McKee Ryan et al. 2005).

Correspondingly, one should expect a rise of life satisfaction when unemployed people take up a new job. On average, this is the case indeed, but, as will be shown later, many of the previously unemployed report either unchanged or lower levels of life satisfaction after finding a new job. Of course, factors not related to the employment situation could be responsible. However, it could also be caused by unsatisfying, 'bad' jobs of low quality. This is the main question we will address in this paper: Are there in fact jobs which such low quality that remaining unemployed may be better, or at least no worse for the overall level of well-being? Is it possible to single out particular job characteristics, such as low wages, or a particular combination of job features that would constitute 'bad' jobs?

It is obvious that this question is important for labor market policies. Layard (2004), in his paper on 'Good jobs and bad jobs', claims that "human happiness ${ }^{1}$ is more affected by whether or not one has a job than by what kind of job it is", and concludes: "Thus, when jobs are at hand, we should insist that unemployed people take them. This involves a much more pro-active placement service and clearer conditionality than applies in many countries." However, this conclusion is still disputed, as is the empirical evidence. Previous case studies, reviewed below, were based on relatively few observations, which restricts the application of appropriate econometric techniques. Furthermore, most studies use a relatively narrow and somewhat arbitrary concept of job quality.

\footnotetext{
${ }^{1}$ Layard (2004) does not distinguish between 'happiness' and 'life satisfaction'.
} 
We try to contribute to this debate by utilizing a large representative panel survey for Germany. Since 1984, the German Socio-Economic Panel (GSOEP) has continuously collected self-reported life satisfaction scores of participants and contains information on various job and worker characteristics, allowing to define job quality in alternative ways. We make use of the panel structure of the data and follow individuals over time, which allows us to control for unobserved, time-invariant individual effects. From the GSOEP we select persons observed as unemployed in a given year $t_{0}$ between 1990 and 2006 in West Germany. For this group, we analyze life satisfaction scores the following year $t_{1}$ depending on whether people are still unemployed or have found a (full-time) job. In the latter case, the role of job quality is investigated. We only consider transitions to full-time jobs, since in this case the impact on life satisfaction is expected to be more clear-cut than in the case of commencing part-time employment. We also expect gender differences to be less important when focusing on full-time jobs, which allows us two analyze both sexes jointly in a multivariate setting.

Our main result is that we cannot identify a single job feature, nor a combination of such features that constitute such low quality jobs that remaining unemployed would be the better choice for the individual. On the contrary, the bulk of our evidence shows that even low quality jobs are associated with higher life satisfaction, and this effect is statistically significant for most specifications of 'bad' jobs.

The observed increase in life satisfaction could also partly be the result of self-selection, as some unemployed may have a stronger preference for work than others and consequently gain more from starting a job. We cannot fully exclude this possibility, but will present evidence that self-selection seems to play only a minor role for the results and that the observed rise in life satisfaction is by and large a causal effect of re-employment.

Moreover, we follow people over 2 years to see whether there is adaptation or habituation to employment. Adaptation, defined as "reduction in the affective intensity of favorable or unfavorable circumstances" (Frederick and Loewenstein 1999), has already been investigated in some studies with regard to unemployment (for a recent survey, see Clark 2006). The underlying hypothesis of these studies is that with longer unemployment duration the negative effects on well-being could decrease, because people learn how to live with unemployment. Similarly, people could adapt to their new job: At first, they may feel relieved to have successfully escaped unemployment, but over time they may become more and more aware of the unpleasant circumstances of their job. ${ }^{2}$ We test this hypothesis by comparing life satisfaction scores between $t_{0}$ and $t_{2}$ for those who have found employment in $t_{1}$ and are still employed in $t_{2}$ and examine whether higher satisfaction levels are likely to persist. We find no evidence for habituation.

\footnotetext{
${ }^{2}$ Evidence of habituation has been found in the case of other events which usually raise happiness levels, such as marriage or a sudden rise in income.
} 
The paper is structured as follows: In Section "Job Quality-Dimensions and Indicators" we discuss dimensions and indicators for job quality and propose alternative approaches to measure job quality. Section "Theoretical Considerations and Previous Evidence" reviews existing theory and empirical evidence. Section "Data and Methodology" discusses the data and our estimation approach. In Section "Results" we present our results and Section "Conclusions" concludes.

\section{Job Quality—Dimensions and Indicators}

A crucial question for our analysis is: What describes a good or bad job? Unfortunately, job quality is not a clearly defined concept, and hence, it is difficult to quantify and measure. Obviously, many aspects of an employment relationship matter. The European Commission (2001), which highlights the importance of job quality as part of the European Employment Strategy ("more and better jobs!"), defines job quality as "a relative concept regarding a job-worker-relationship, which takes into account both objective characteristics related to the job and the match between worker characteristics [...] and job requirements [...]. It also involves subjective evaluation of these characteristics by the respective worker."

This broad definition permits us to distinguish between an objective and a subjective dimension of job quality. The former is mirrored by observable characteristics, such as wages, job security, working time arrangements, and by the fit between acquired and required human capital; the latter is mirrored by the subjective perception of these characteristics.

To start with objective features, our data provide a number of job-related information, e.g. on pay, working hours as well as basic contract terms. Since the provision of a secure income is considered as the main "manifest" function of work (Jahoda 1982), we put particular emphasis on wages and job security, and classify jobs with respect to the type of employment contract (permanent or fixed term contract) and whether or not jobs are low paid. According to the theory of compensating wage differentials, high-wage jobs are not necessarily better in terms of job quality and resulting welfare levels, since higher wages are paid to compensate for any unpleasant or hazardous working conditions. ${ }^{3}$ In line with traditional labor economics, low-wage jobs should be no worse than better-paid jobs in terms of resulting welfare levels. However, the theory of labor market segmentation, introduced by Doeringer and Piore (1971), challenges the neo-classical labor market model and assumes the existence of at least two distinct labor market segments with rather different employment characteristics and allocation mechanisms: A primary (or core) segment of 'good jobs' with relatively high wages and employment security, and a

\footnotetext{
${ }^{3}$ For a comprehensive discussion of compensating wage differentials, see Rosen (1986).
} 
secondary segment of 'bad jobs', mostly insecure and low-paid. ${ }^{4}$ According to this approach, wages and job quality are expected to be positively correlated, and this view also prevails in recent studies on job quality (Cabral Vieira et al. 2005; Diaz-Serrano and Cabral Vieira 2005; Howell and Okatenko 2008).

Regarding the subjective perception of job quality, we follow the approach by Leontaridi and Sloane (2001), Clark (2005) and a number of case studies carried out by psychologists (see review in McKee-Ryan et al. 2005) where job satisfaction scores are used as a proxy for job quality. Objective (observable) features of the current job and job satisfaction can be expected to be strongly correlated. Therefore, we do not estimate the effects of wages and employment security jointly with job satisfaction, but separately. Moreover, job quality as a 'relative concept' (European Commission 2001) is also influenced by the match between the worker characteristics and job requirements. Closely related to the job match is the influence of the employment history of an individual before she became unemployed. More specifically, we expect that the characteristics of the pre-unemployment job, provided there was such a job, will influence the perception of the current job-a comparison effect. To give an example: Commencing a low wage job out of unemployment may be more dissatisfying for someone who had a better paid job before. We rely on various aspects of the current and the previous job, explained in more detail in Section "The Role of Job Quality", to investigate the relevance of this comparison effect.

\section{Theoretical Considerations and Previous Evidence}

The psychological well-being of the unemployed compared to the well-being of those employed in 'bad' and 'good' jobs, however specified, has already been investigated in a number of studies. As to theoretical considerations, there is the influential approach of Jahoda (1982). She distinguished between "manifest" functions of work (mainly provision of income) and "latent" functions such as social interaction, time structuring and personal identity. Jahoda (1982) claimed that the latent functions are much more important for the mental wellbeing than the manifest functions. Even in insecure low paid jobs workers can participate in these latent benefits. From this perspective, any job is better than no job.

Jahoda's views were challenged by other researchers. Liem (1992) claimed that the psychological costs of accepting an unsatisfactory job are often greater than those incurred by remaining unemployed, because the worker gives up personal control and incurs damage to his or her sense of self. Fryer's agency theory argues that the mental well-being suffers from a restriction of personal

\footnotetext{
${ }^{4}$ The segmentation approach also distinguishes between internal and external markets. This distinction partly coincides with the distinction between a primary and a secondary sector, but allows for further segmentation within the primary sector (e.g. firm-specific or occupation-specific labor markets).
} 
agency caused by financial deprivation, which prevents affected workers from planning a meaningful future (Fryer 1986). In this perspective, the transition to a low wage job is only preferable to unemployment if it provides more income.

The empirical evidence concerning the debate is mixed. First, there is evidence from cross-sectional studies. A case study, carried out in Australia, compared 193 unemployed people and 206 low wage earners and concluded that the latter are significantly better off than the former in terms of life satisfaction and other dimensions of mental well-being (Hassall et al. 2004). Theodossiou (1998) obtained similar results for Britain with a larger sample drawn from the 1992 wave of the British Household Panel Survey (BHPS). In contrast, a study based on the first wave on the Australian household panel HILDA focused on reported job satisfaction as indicator for employment quality and found "that being in employment but in a job in which one has low job satisfaction has an even greater detrimental effect on reported life satisfaction than unemployment" (Dockery 2003).

However, in cross-sectional comparisons it cannot be excluded that the jobless differ systematically from the employed in unobserved characteristics that may in turn influence life satisfaction. Hence, longitudinal studies which follow the same individuals over time may be more revealing. Such studies have been carried out by psychologists and sociologists. Leana and Feldmann (1995) surveyed 59 male laid-off workers in the US immediately after job loss and one year later. They show that, on average, the still unemployed showed greater psychological distress than the re-employed, but also find great differences in life satisfaction between satisfactorily and unsatisfactorily reemployed workers. Wanberg (1995) carried out a longitudinal study on 129 unemployed people and finds that both persons who remained unemployed and those who found a dissatisfying job reported no changes in mental health. In larger case studies, O'Brien and Feather (1990) and Winefield et al. (1993) surveyed two panels of Australian school-leavers in the 1980's; both studies found that those who had found 'good' jobs were clearly more satisfied than those who were unsatisfactorily employed, whereas the latter were not better off than those who were unemployed, in terms of life satisfaction and other indicators of psychological well-being. In any case, the focus of these two studies is on transitions between school and working life, and not between unemployment and 'good' respectively 'bad' jobs, which is the focus of this paper.

\section{Data and Methodology}

The empirical analysis is based upon the German Socio-Economic Panel (GSOEP) which is a representative longitudinal survey of private households since 1984. All household members aged 16 and above are interviewed on an annual basis. A multitude of topics are covered, among them individual 
employment histories, earnings and various satisfaction dimensions, e.g. life, job and health status. ${ }^{5}$

Our main analysis will be based on a sample consisting of people aged between 20 and 60 years and residing in West Germany ${ }^{6}$ who reported to be unemployed at the time of the interview in a particular year $t_{0}$ and were either full-time employed or still unemployed the following year $t_{1}$. Individuals who commenced part-time jobs, started their own business or became economically inactive after the unemployment spell have been excluded from the main analysis. $^{7}$

Pooling all valid observations across the years 1990 to 2006 yields a sample size of 9,954 person-year observations. In a second step, we will also look at medium-term effects. We therefore construct a second sample which follows individuals over 2 years and consists of 9,066 person-year observations. ${ }^{8}$

Table 1 presents summary statistics of variables typically used in happiness regressions and which will enter our empirical models as standard controls. Satisfaction levels with life and health are measured on a scale ranging from zero to ten. Respondents are asked to answer questions like: 'How dissatisfied or satisfied are you with your life overall?' where zero indicates complete dissatisfaction and ten complete satisfaction. In our sample, average life satisfaction is around 6 and satisfaction with health is somewhat higher (6.2). We will consider standard control variables like age, education, household income and certain household characteristics in all our regressions. To capture economic conditions at a regional level, we add state-specific unemployment rates obtained from the Federal Employment Office. Table 1 also reveals that the majority of people in our sample will remain unemployed since only $23 \%$ are full-time employees the following year.

Various approaches of measuring the concept of job quality are discussed in the literature and we will pursue some of these suggestions in our empirical analysis. First, we use information on self-reported job satisfaction as an indicator of job quality. Second, jobs are classified according to their type of contract, i.e. permanent or fixed-term, and whether jobs are low paid. ${ }^{9}$ This way, we hope to assess the quality of a new job in a more impartial way. Third,

\footnotetext{
${ }^{5}$ For further information on the GSOEP, see Haisken-DeNew and Frick (2005). The data used in this paper was extracted using the Add-On package PanelWhiz for Stata ${ }^{\circledR}$. PanelWhiz (http://www.PanelWhiz.eu) was written by Dr. John P. Haisken-DeNew (john@PanelWhiz.eu). See Haisken-DeNew and Hahn (2006) for details. The PanelWhiz generated DO file to retrieve the data used here is available from the authors upon request. Any data or computational errors in this paper are our own.

${ }^{6}$ Residents of East Germany have been excluded since the East German economy and labor market underwent radical structural changes throughout the 1990's.

${ }^{7}$ As shown later, the respective number of observations was relatively low and basic summary statistics suggest that people who leave unemployment to work part-time or to become economically inactive differ systematically from other labor market participants.

${ }^{8}$ Most of our analysis will rely on the sample which traces individuals for one year only.

${ }^{9}$ If wages fell below two thirds of the median wage of all full-time employees in a given year they are considered low pay.
} 
Table 1 Summary statistics of standard controls

Notes: Average values at $t_{1}$ are shown. Satisfaction scores run from 0 to 10 .

Cohabitation includes unmarried couples. If applicable, standard deviations are reported in parentheses

\begin{tabular}{lll}
\hline Satisfaction with & & \\
$\quad$ Life & 5.98 & $(2.06)$ \\
$\quad$ Health status & 6.18 & $(2.44)$ \\
Socio-economic characteristics & & \\
$\quad$ Age & 42.7 & $(12.37)$ \\
$\quad$ Net household income (current $€)$ & 1735 & $(1025)$ \\
Female & 0.40 & \\
Cohabitation & 0.74 \\
$\quad$ Household with children & 0.39 \\
Formal education & & \\
$\quad$ No, low or unknown & 0.37 \\
$\quad$ ISCED 3-4 & 0.51 \\
$\quad$ ISCED 5+ & 0.11 & \\
Labor market related (\%) & & \\
$\quad$ Full-time job at $t_{1}$ & 23.4 \\
$\quad$ Federal state unemployment rate & 9.96
\end{tabular}

we will explore measures of 'job fit' and occupational prestige of the new position. For this, we check whether people work in the occupation they were trained for. We also compare the required qualification of the new job with the actual qualification level to find out whether people are overeducated for the new position. ${ }^{10}$ Regarding occupational prestige, we rely on two measures. Respondents are asked to indicate the level of occupational autonomy in their current job on a scale from 1 (low) to 5 (high) and we assume that more autonomy in occupational actions corresponds to higher occupational prestige. Alternatively, we rely on the Treiman Standard International Occupational Prestige Scale which assigns status scores to all occupations classified in the International Standard Classification of Occupation 1988 (ISCO88). ${ }^{11}$ Last, we utilize a number of variables provided by the GSOEP where respondents give feedback regarding certain characteristics of their current job vis-a-vis their previous job, like e.g. kind of activity, pay, advancement possibilities, flexibility and use of professional knowledge. We will separately test for the relationship between some of these job aspects and life satisfaction, but will also create an index combining the information contained in these variables. Operationalizing job quality in these various ways will help us to identify characteristics of 'bad jobs', i.e. jobs that presumably are not associated with an increase in life satisfaction. In addition, we will test for differences among those who started a new job to see whether those in 'good' jobs are significantly better off than those in 'bad' jobs.

\footnotetext{
${ }^{10}$ In order to assess job requirements, respondents are asked to describe the type of training necessary for the current job. To construct a binary variable indicating overeducation, categories "no particular training needed", "just quick introduction", "fairly lengthy training at work place", "taking certain courses" are summarized and assumed to correspond to ISCED levels 1 and 2. If "career training" was needed, we assume that levels 3 or 4 would match those requirements. Finally, "higher education" is equated with ISCED levels 5 and 6 . For a comprehensive discussion of overeducation and related concepts, see Green et al. (2002).

${ }^{11}$ For more information, please refer to Ganzeboom and Treiman (1996), Treiman (1977).
} 
Table 2 illustrates the distributions of various job characteristics among those employed at $t_{1}$. Self-reported ' is also measured on a zero to ten scale. Scores between 0 and 4 correspond to low, 5-7 to medium and 8-10 to high levels of job satisfaction. Around a third of all jobs commenced after unemployment were on a fixed term basis. Regarding earnings, almost $40 \%$ of jobs following an unemployment spell fell below the low pay threshold and $17 \%$ of all jobs combined these two 'bad' job properties. Next, we turn to our indicators of potential job mismatch. Only around $40 \%$ will

Table 2 Distribution of job characteristics among full-time employees

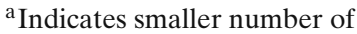
observations due to item non-response. At most, sample size is reduced by around $20 \%$ when looking at the comparisons between current and previous job

\begin{tabular}{|c|c|}
\hline Number of full-time employees at $t_{1}$ & 1,167 \\
\hline \multicolumn{2}{|l|}{ Self-reported job satisfaction } \\
\hline High & 0.49 \\
\hline Medium & 0.37 \\
\hline Low & 0.14 \\
\hline \multicolumn{2}{|l|}{ Type of contract, pay } \\
\hline Fixed term & 0.35 \\
\hline Low pay & 0.39 \\
\hline Fixed term and low pay & 0.17 \\
\hline \multicolumn{2}{|l|}{ Job fit ${ }^{\mathrm{a}}$} \\
\hline Work in occupation trained for & 0.42 \\
\hline Overeducated & 0.36 \\
\hline \multicolumn{2}{|l|}{ Level of autonomy } \\
\hline High & 0.57 \\
\hline Low & 0.43 \\
\hline \multicolumn{2}{|l|}{ Treiman score ${ }^{a}$} \\
\hline High & 0.32 \\
\hline Medium & 0.36 \\
\hline Low & 0.32 \\
\hline \multicolumn{2}{|c|}{ Comparison of current and previous job regarding: ${ }^{a}$} \\
\hline \multicolumn{2}{|c|}{ Kind of activity } \\
\hline Improved & 0.43 \\
\hline Same & 0.41 \\
\hline Worse & 0.16 \\
\hline \multicolumn{2}{|l|}{ Earnings } \\
\hline Improved & 0.41 \\
\hline Same & 0.28 \\
\hline Less & 0.31 \\
\hline \multicolumn{2}{|l|}{ Advancement possibilities } \\
\hline Improved & 0.25 \\
\hline Same & 0.55 \\
\hline Worse & 0.20 \\
\hline \multicolumn{2}{|l|}{ Workload } \\
\hline Improved & 0.25 \\
\hline Same & 0.48 \\
\hline Worse & 0.26 \\
\hline \multicolumn{2}{|l|}{ Working hours regulations } \\
\hline Improved & 0.30 \\
\hline Same & 0.47 \\
\hline Worse & 0.23 \\
\hline \multicolumn{2}{|l|}{ Use of professional knowledge } \\
\hline Improved & 0.27 \\
\hline Same & 0.49 \\
\hline Less & 0.24 \\
\hline
\end{tabular}


Table 3 Life satisfaction and labor market status

\begin{tabular}{|c|c|c|c|c|}
\hline Labor market status at $t_{1}$ : & $\begin{array}{l}\text { Full-time } \\
\text { job }\end{array}$ & Unemployed & $\begin{array}{l}\text { Part-time } \\
\text { job }\end{array}$ & $\begin{array}{l}\text { Out of } \\
\text { labor force }\end{array}$ \\
\hline \multicolumn{5}{|l|}{ Life satisfaction at $t_{0}$} \\
\hline Mean & 5.79 & 5.81 & 6.31 & 6.43 \\
\hline Standard error & 0.06 & 0.03 & 0.11 & 0.08 \\
\hline $\mathrm{N}$ & 1167 & 3810 & 344 & 715 \\
\hline \multicolumn{5}{|c|}{ Change in life satisfaction from $t_{0}$ to $t_{1}$} \\
\hline Mean & +0.92 & -0.05 & +0.34 & -0.05 \\
\hline Standard error & 0.06 & 0.03 & 0.11 & 0.07 \\
\hline $\mathrm{N}$ & 1167 & 3810 & 344 & 715 \\
\hline \multicolumn{5}{|c|}{$\begin{array}{l}\text { Change in life satisfaction from } t_{1} \text { to } t_{2} \\
\ldots \text { if employed at } t_{2}\end{array}$} \\
\hline Mean & +0.08 & +0.94 & - & - \\
\hline Standard error & 0.07 & 0.12 & & \\
\hline $\mathrm{N}$ & 623 & 313 & & \\
\hline \multicolumn{5}{|l|}{$\ldots$ if unemployed at $t_{2}$} \\
\hline Mean & -1.01 & +0.02 & - & - \\
\hline Standard error & 0.17 & 0.05 & & \\
\hline $\mathrm{N}$ & 175 & 1911 & & \\
\hline
\end{tabular}

get employed in the same occupation they were trained for; hence, for the majority of the unemployed the new job probably demands a different set of skills. We are particularly interested whether people resent the fact of being 'underemployed', i.e. the acquired level of education and training exceeds the required qualification level. In our sample, more than a third report being overqualified for their new position. Regarding our measures of occupational prestige, we find that $43 \%$ report a low level of occupational autonomy which we will equate with lower levels of occupational prestige. When relying on the Treiman prestige scale, jobs are almost evenly distributed across the three categories indicating low, medium or high occupational prestige. ${ }^{12}$ Finally, looking at the comparisons between current and previous job characteristics, there seems to be a great deal of stability (except for earnings), but the share of people reporting positive or negative changes remains substantial.

Before turning to the empirical approach and results of the multivariate analysis, we briefly discuss some more descriptive results. Table 3 confirms the well-known differences in life satisfaction among labor force participants. The first panel reports the level of life satisfaction at year $t_{0}$ (i.e. when everyone is unemployed), broken down by labor market status the following year. At $t_{0}$, there are no systematic differences in life satisfaction scores between people who will be full-time employed at $t_{1}$ and people who will remain unemployed. However, people with part-time jobs and those who will be out of the labor force seem to be less affected by unemployment as their

\footnotetext{
${ }^{12}$ Our assumption that low levels of autonomy correspond to low occupational prestige is supported by a correlation coefficient of 0.67 between these two variables.
} 
average life satisfaction scores are significantly higher at $t_{0}$. It is interesting to note that for these two groups the share of women is around $80 \%$, whereas among other groups of labor market participants the gender ratio is more balanced. Also, the number of observations is substantially smaller. Looking at the changes in life satisfaction between $t_{0}$ and $t_{1}$, only finding a job is associated with a significant rise and the increase is much bigger for those in full-time employment. Again, these results indicate that certain groups are less attached to the labor market and hence are likely to respond differently to the quality of available jobs. In order to obtain robust and significant results, the main empirical analysis will only consider individuals who are either full-time employed or still unemployed at $t_{1}$.

When following people over 2 years (results shown in second panel), we observe a similar increase in life satisfaction for those who find full-time employment in $t_{2}$. Being continuously employed seems to further increase life satisfaction although not significantly in a statistical sense. On the other hand, people who become unemployed again in $t_{2}$ realize a pronounced decline in their satisfaction level and those who have never been employed while being observed in our sample report on average rather stable life satisfaction levels.

As a whole, the group of the newly-employed seems to be better off, but a more detailed look at the distribution of changes in life satisfaction tells a somewhat different story. As can be seen from Fig. 1, among the group of full-time employees $21 \%$ report the same and $22 \%$ report a lower score in life satisfaction in $t_{1}$ as in $t_{0}$. For sub-samples like low wage earners, the picture looks rather similar. The share of low wage earners reporting an increase in life satisfaction is somewhat lower, but still lies above $50 \%$. Clearly, other determinants may have changed as well and in order to correctly identify the impact of the employment status a multivariate analysis is required. The relatively large number of people reporting unchanged or even lower life satisfaction scores despite having found employment poses the question whether the quality of the new job, i.e. certain characteristics like being low paid, plays a crucial role in their assessment.

Fig. 1 Feeling better or worse after re-employment?

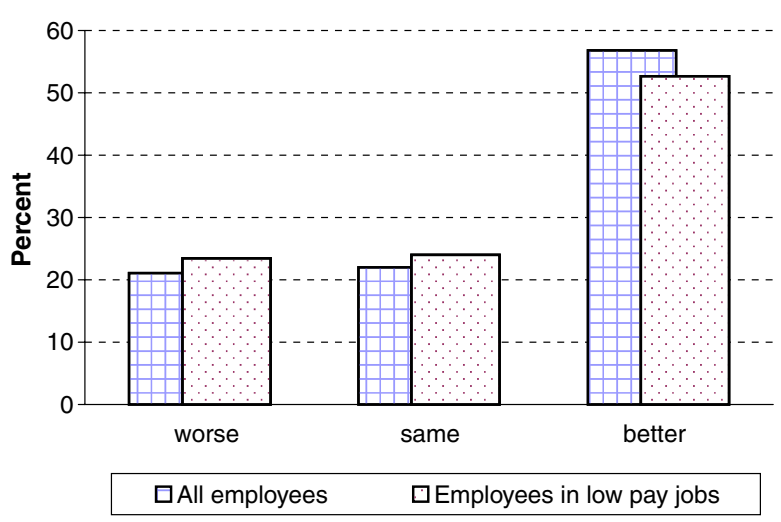


As outlined above, self-reported satisfaction levels regarding current employment, health or life overall are reported on a scale running from zero to ten. Hence, individual satisfaction scores can be ranked from low to high and the acquired information has an ordinal structure. Despite this, cardinal models like OLS and fixed effects panel estimators are frequently applied to this kind of data. From a theoretical point of view, strong assumptions regarding interpersonal comparability are necessary to support a cardinal interpretation of subjective well-being data. Previous research has shown that in order to attain unbiased estimates it is of less importance whether results have been obtained from cardinal or ordinal models but whether the problem of unobserved heterogeneity has been addressed appropriately (Ferreri-Carbonell and Frijters 2004). Since any subjective assessment may mirror inherent personality traits that cannot be observed and do not change over time, it seems sufficient to address individual time-invariant unobservables to arrive at unbiased estimates.

In the context of life satisfaction being measured on an ordinal scale, discrete choice models allowing for fixed effects seem the most appropriate choice. Few studies built on the conditional logit model by Chamberlain (1980) and developed an algorithm to estimate ordered logit models with fixed or random effects (e.g. Das and van Soest 1999; Ferrer-i-Carbonell and Frijters 2004). ${ }^{13}$ A computationally less laborious method which also follows the logic of Chamberlain's estimator has been applied by e.g. Booth and van Ours (2008) and Kassenboehmer and Haisken-DeNew (2009) and we will mainly follow their approach. For this, we transform individual life satisfaction scores $Y_{i t}$ into a binary variable which equals one when a person's life satisfaction score at time $t$ is above the individual average and zero otherwise: ${ }^{14}$

$$
\begin{aligned}
& y_{i t}=\left\{\begin{array}{lll}
0 & \text { if } \quad Y_{i t} \leq \bar{Y}_{i} \\
1 & \text { if } \quad Y_{i t}>\bar{Y}_{i}
\end{array}\right. \\
& \text { with } \bar{Y}_{i}=\sum Y_{i t} / T .
\end{aligned}
$$

We will regress the binary variable $y_{i t}$ indicating improvements in life satisfaction on the set of standard controls and indicators of job quality to find out whether certain job characteristics are likely to attenuate the otherwise positive effect of having found new employment. The fixed effects logit model can be written as

$$
\operatorname{Prob}\left(y_{i t}=1 \mid x_{i t}\right)=\frac{e^{\alpha_{i}+x_{i t}^{\prime} \beta}}{1+e^{\alpha_{i}+x_{i t}^{\prime} \beta}} .
$$

\footnotetext{
${ }^{13}$ For an application of the estimators on determinants of job satisfaction, see D'Addio et al. (2007).

${ }^{14}$ The average level of individual life satisfaction $\bar{Y}_{i}$ was calculated from satisfaction scores reported between 1985 and 2007.
} 
The unconditional maximum likelihood estimates for $\alpha_{i}$ and, hence, $\beta$ will be inconsistent due to the incidental parameters problem (Greene 2008). Chamberlain's estimator is based on the conditional likelihood function which does no longer depend on the incidental parameters $\alpha_{i}$ and allows for an unbiased estimation of the coefficients $\beta$. The model is identified by those individuals who realize a change in their dependent variable over time, e.g. $y_{i, 1990}=0, y_{i, 1991}=1$, but individuals with no change in the dependent variable will not contribute to the likelihood function and will not be included in the estimation. ${ }^{15}$

\section{Results}

Re-employment and Life Satisfaction

Table 4 illustrates the results obtained from the conditional logit estimator using the standard set of control variables. The strong and positive correlation between finding a job and life satisfaction shown in Table 3 persists in a multivariate setting, both for the whole sample and when tested separately for men and women. ${ }^{16}$

One concern regarding the reliability of this result could be the underlying sample structure. Since we have pooled across individuals regardless how many times (and years) they have been unemployed between 1990 and 2006, people who are unemployed for several years will enter the sample more than once. This also means that long-term unemployed and people who repeatedly lost their job are overrepresented in our sample. To test whether this particular data structure is likely to influence our results, we re-run all regressions on randomly drawn samples with only one $\left(t_{0}, t_{1}\right)$ sequence per individual. Although the share of the unemployed in $t_{1}$ declines from $76 \%$ to around $67 \%$, the main results remain remarkable stable as can be seen from Table 4 , column $4 .^{17}$

Another related aspect of the relationship between life satisfaction and reemployment is the potential bias due to self-selection into employment. People have heterogeneous preferences regarding employment and those with strong

\footnotetext{
${ }^{15}$ To see whether our results are sensitive to the loss of information due to transforming life satisfaction scores into a binary variable and the loss of observations related to applying a conditional logit estimator, we have re-run all regressions applying a traditional fixed effects panel estimator. Results are very similar to the ones reported here and available on request. For a more detailed discussion on the conditional logit estimator, please refer to Chamberlain (1980) and Greene (2008).

${ }^{16}$ Since the gender-specific results for the overall employment effect as well as applied job quality indicators are very similar, we decided to only report results obtained from the pooled sample. The gender-specific results are available on request.

${ }^{17}$ Since our initial regression did control for individual fixed effects, we probably could already account for the bulk of unobserved heterogeneity.
} 
Table 4 Determinants of life satisfaction

\begin{tabular}{lcccc}
\hline & (1) All & (2) Women & \multicolumn{1}{c}{ (3) Men } & (4) Random sample \\
\hline Age & $-0.044^{* * *}(0.017)$ & $-0.038(0.027)$ & $-0.046^{* *}(0.022)$ & $-0.050(0.083)$ \\
ISCED 3-4 & $0.163(0.235)$ & $-0.007(0.470)$ & $0.208(0.268)$ & $0.050(0.588)$ \\
ISCED 5+ & $-0.460(0.537)$ & $-0.263(0.827)$ & $-0.618(0.734)$ & $-0.349(0.848)$ \\
Cohabitation & $0.188(0.166)$ & $0.147(0.251)$ & $0.285(0.223)$ & $-0.110(0.263)$ \\
$\begin{array}{l}\text { Household with } \\
\quad \text { children }\end{array}$ & $0.078(0.178)$ & $0.325(0.258)$ & $-0.045(0.232)$ & $0.221(0.319)$ \\
$\begin{array}{l}\text { Log net household } \\
\text { income (current } €)\end{array}$ & $0.452^{* * *}(0.112)$ & $0.418^{* *}(0.178)$ & $0.462^{* * *}(0.144)$ & $0.430^{* * *}(0.180)$ \\
$\begin{array}{l}\text { Health status } \\
\text { State unemployment }\end{array}$ & $0.320^{* * *}(0.026)$ & $0.454^{* * *}(0.044)$ & $0.250^{* * *}(0.032)$ & $0.280^{* * *}(0.034)$ \\
$\quad$ rate & $-0.127^{* * *}(0.034)$ & $-0.096^{*}(0.050)$ & $-0.143^{* * *}(0.045)$ & $-0.106^{* *}(0.063)$ \\
$\begin{array}{l}\text { Full-time employed } \\
\text { Observations }\end{array}$ & $1.094^{* * *}(0.099)$ & $1.103^{* * *}(0.178)$ & $1.103^{* * *}(0.118)$ & $1.111^{* * *}(0.157)$ \\
Pseudo- $R^{2}$ & 7382 & 2864 & 4518 & - \\
\hline
\end{tabular}

Notes: Coefficients of conditional logit regressions are shown. Standard errors (corrected for repeated observations) are shown in parentheses. Reference categories: Single, no children living in household, no, low or unknown level of education, still unemployed. The results shown in column 4 have been obtained from a Monte Carlo simulation based on 1,000 replications

${ }^{*} p<0.1 ;{ }^{* *} p<0.05 ;{ }^{* * *} p<0.01$

preferences for work are more likely to find and accept a job-even one of low quality. For the same reason, they may gain more from taking any job (i.e. realise and report higher welfare levels) than those with weak preferences for work. Hence, the observed increase in life satisfaction among the re-employed could simply reflect different preferences.

Given the data at hand, we cannot directly control for self-selection and isolate its potential effect. However, we can put forward some empirical evidence suggesting that the effect is unlikely to be very pronounced. If it were, we would expect that those with strong work preferences will be overrepresented among the re-employed who in turn should have been particularly unhappy while being unemployed. As shown in Table 3, this is not the case: at $t_{0}$ there is only a small, statistically insignificant difference between 'movers' (employed at $t_{1}$ ) and 'stayers' (unemployed at $t_{1}$ ). Admittedly, this argument cannot fully rule out any potential selection bias since it is based on a crosssectional comparison of satisfaction levels, but it indicates that self-selection only seems to play a minor role and higher life satisfaction is largely a causal effect of re-employment.

Regarding other covariates, we find that age has a negative effect, but is only significant among men. Probably due to little variation between years, for some of the standard controls like educational level, being in a stable relationship and whether children live in the household we cannot identify significant effects. On the other hand, higher household net incomes and higher health satisfaction levels have positive effects on life satisfaction, however, the magnitude of the effects are somewhat different for men and women. Overall labor market conditions are proxied by federal unemployment rates 
and results suggest that higher levels of regional unemployment lower the probability of life satisfaction improvements, especially for men. ${ }^{18}$

\section{The Role of Job Quality}

In order to gain a better understanding of the role job quality plays for life satisfaction, we will turn to the results presented in Table $5 .{ }^{19}$ Panel A shows the results when using self-reported job satisfaction levels, earnings and type of contract as an indicator of job quality. Regarding job satisfaction scores, the coefficients for categories low, medium and high are all positive indicating that the probability of being better off increases with the level of job satisfaction, but the effect is insignificant for the lowest category. Hence, those least satisfied with their new position are not likely to be better off than the unemployed. We then test whether certain employment conditions allow us to again identify a group of workers that will not be better off than the unemployed. As can be seen from columns 2-4, we can reject the hypothesis that low wage jobs or temporary employment contracts are associated with lower life satisfaction scores. On the contrary, people employed under these conditions still have significantly better chances of improvements in life satisfaction than the unemployed. Even for the group of workers with temporary low wage jobs (i.e. combining both dimensions) we still find a significant positive effect on life satisfaction. This suggests that other job characteristics, if any, result in low levels of job satisfaction.

Testing for differences among full-time employees reveals that only those in higher wage jobs are significantly better off than those in low wage jobs. For all other sub-samples of workers shown in Panel A the coefficients are not statistically different from each other.

Next, we turn to the measures of job match and occupational prestige (Panel B). People who work in professions which obtained low prestige scores according to the Treiman scale or report low levels of autonomy in occupational actions are still significantly better off than the unemployed (columns 1 and 2). The picture remains much the same when looking at job fit measures, despite the fact that the professional mismatch in our sample seems substantial: More than a third report that they feel overqualified for the new position and around $40 \%$ do not find work in the occupation they were trained for. As shown in columns 3 and 4, even these groups of workers are more likely to realize an increase in life satisfaction. Comparing the differences among full-time employees, we observe larger coefficients for the presumably better categories in three cases, however, most of these differences are not

\footnotetext{
${ }^{18} \mathrm{We}$ also used individual unemployment duration as an explanatory variable, but results were never significant in a fixed effects setting.

${ }^{19}$ Since our main focus is on the role of job quality on life satisfaction, we do not report the coefficients of the standard control variables. We have also split the sample by gender and run all regressions for men and women separately. Results with regard to job quality are often very similar.
} 


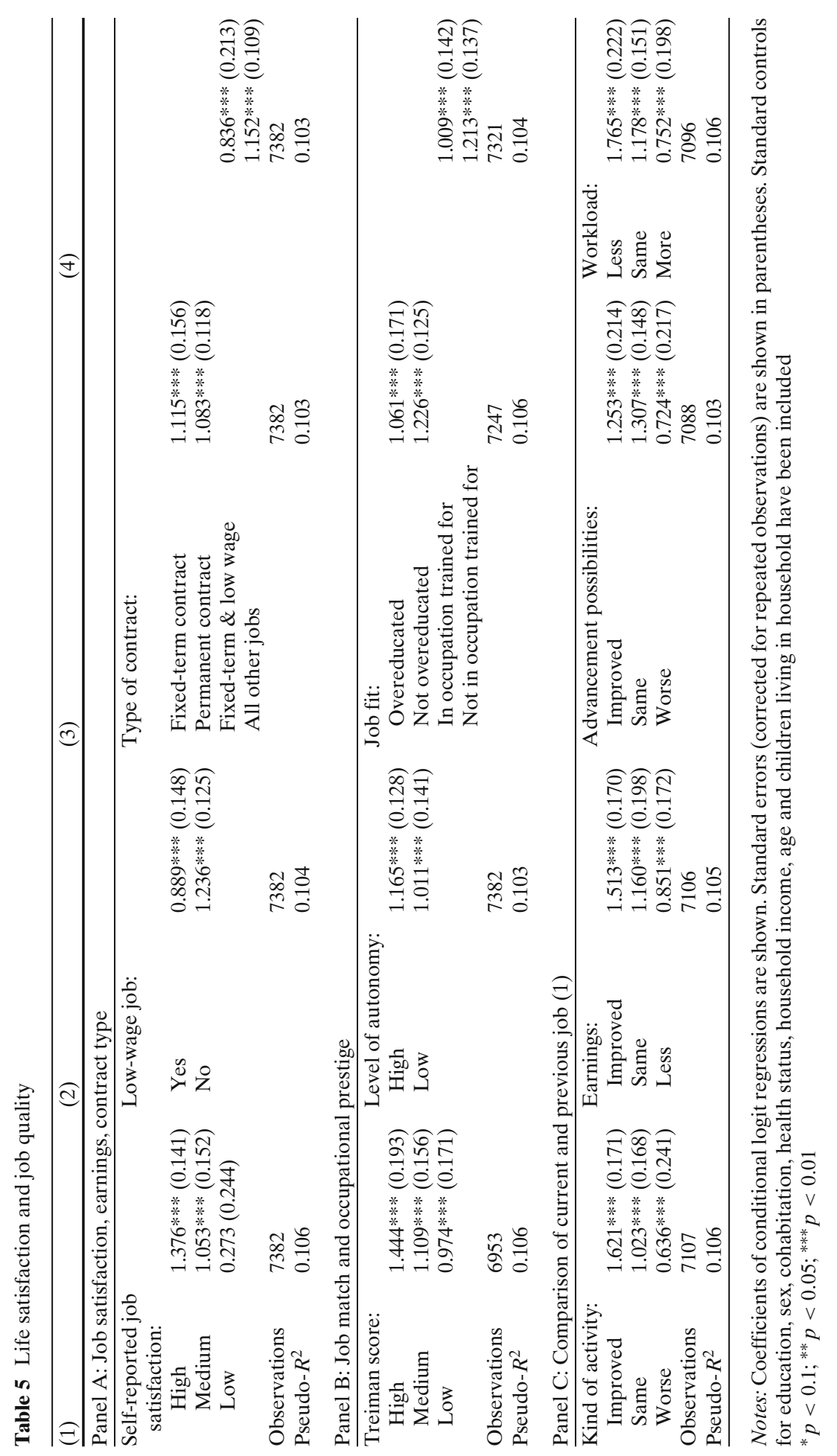


statistically significant. Only when comparing jobs with high and low Treiman prestige scores we can detect a significant difference.

Our final approach to operationalizing job quality rests upon a comparison of certain aspects of the current job versus the previous job. Respondents are asked to indicate whether e.g. earnings, kind of activity, workload and career prospects have improved, worsened or are about the same. ${ }^{20}$ Table 5, Panel C, shows the results when testing separately for the relationship between some of these assessments and life satisfaction. As one would expect, improved or similar working conditions are positively correlated with life satisfaction. When people encounter a worse work environment, they are still significantly better off than the unemployed, but significantly less so than respondents with improved working conditions.

Testing for different aspects of the new position separately may not be the appropriate way to identify 'bad' jobs. In order to control for a number of relevant criteria simultaneously, we construct an index which combines the information of six variables comparing the current with previous the job. In particular, we will rely on comparative data regarding the kind of activity, earnings, advancement possibilities, workload, working hours regulations and use of professional knowledge (see also Table 2). Applying multiple correspondence analysis allows us to map 58\% of the variables' principal inertia in one dimension. To adequately represent the distribution of the index scores, we rather consider deciles than one continuous variable reflecting the average index value in the empirical analysis. Table 6 presents the results. As indicated by the coefficients obtained for the deciles controls, the index does not have a linear effect on life satisfaction such as that being in a higher decile would correspond to a higher probability of improvements in life satisfaction. Rather, our results suggest a certain threshold effect, since relatively low scores are still associated with higher levels of life satisfaction. Only for the lowest decile, i.e. where the current job is worse than the previous one in many respects, the coefficient remains insignificant, indicating that the positive effect of finding new employment is fully offset by much worse working conditions.

A similar result can be obtained when simply calculating the sum score across all six variables used to construct the index. A sum score of at least 4 will assure that there is no positive significant effect anymore (Table 6, column 2 ). In other words, if the new position was rated worse in four or more aspects, the positive impact on life satisfaction disappears. However, since only $12 \%$ of all jobs in our sample have negative ratings in 4 or more aspects, this result needs to be interpreted with caution.

In a final step, we attempt to identify dimensions for which a joint deterioration will be of particular importance for overall life satisfaction. Combining the 'worse/less' outcomes of all six comparison variables yields 15 pairs of

\footnotetext{
${ }^{20}$ In total, respondents are asked to provide feedback regarding nine aspects. Based on results obtained from a multiple correspondence analysis, we decided on six variables to be used in our empirical analysis.
} 
Table 6 Life satisfaction and job quality: comparison of current and previous job (2)

\begin{tabular}{|c|c|c|c|c|}
\hline & (1) & (2) & (3) & (4) \\
\hline Highest decile & $1.559 * * *(0.331)$ & & & \\
\hline $9^{\text {th }}$ decile & $1.738 * * *(0.338)$ & & & \\
\hline $8^{\text {th }}$ decile & $2.179 * * *(0.427)$ & & & \\
\hline $7^{\text {th }}$ decile & $0.679 * *(0.312)$ & & & \\
\hline $6^{\text {th }}$ decile & $1.180 * * *(0.328)$ & & & \\
\hline $5^{\text {th }}$ decile & $1.101 * * * *(0.296)$ & & & \\
\hline $4^{\text {th }}$ decile & $1.115 * * *(0.349)$ & & & \\
\hline $3^{\text {rd }}$ decile & $1.454 * * *(0.363)$ & & & \\
\hline $2^{\text {nd }}$ decile & $0.902 * * *(0.307)$ & & & \\
\hline Lowest decile & $0.250(0.298)$ & & & \\
\hline All other jobs & & $1.290 * * *(0.120)$ & $1.301 * * *(0.117)$ & $1.299 * * *(0.121)$ \\
\hline $\begin{array}{l}\text { Any four or more aspects } \\
\text { worse than in previous job }\end{array}$ & & $0.404(0.279)$ & & \\
\hline $\begin{array}{c}\text { Worse workload and worse } \\
\text { working hour regulations }\end{array}$ & & & $0.373(0.292)$ & \\
\hline $\begin{array}{l}\text { Worse kind of activity } \\
\text { and less earnings }\end{array}$ & & & & $0.330(0.276)$ \\
\hline Observations & 7078 & 7078 & 7078 & 7078 \\
\hline Pseudo- $R^{2}$ & 0.107 & 0.103 & 0.104 & 0.104 \\
\hline
\end{tabular}

Notes: See Table 5

job characteristics (e.g. worse kind of activity and less use of professional knowledge). Although the number of jobs sharing any of these negative assessments sometimes falls below 100, we are able to identify combinations of bad job assessments that still have a significant positive effect on life satisfaction. In case of eight combinations, however, the coefficient remains insignificant. ${ }^{21}$ We take this as an indicator of job aspects that are particularly important and, if deteriorating jointly, will equalize the positive effect of being full-time employed. Columns 3 and 4 of Table 6 show the results for two of those combinations.

\section{Job Quality and Medium Term Effects}

Closely related to studying determinants of subjective well-being is the question whether or not people adapt to a changed economic or social environment. Also using GSOEP data, Clark et al. (2008) analyze the degree of anticipation and adaptation to six labor market and family events. Controlling for unobserved heterogeneity, they find strong evidence of both lead and lag effects on current levels of life satisfaction suggesting that after some time subjective well-being indicators tend to return to a particular baseline level. Of particular relevance to our study are their results with respect to unemployment. In

\footnotetext{
${ }^{21}$ In particular, combining worse kind of activity with either less earnings or worse workload, or combining worse working hour regulations with either less earnings, worse career options, worse workload, less use of professional knowledge or worse kind of activity and, finally, combining worse career options with worse workload will lead to insignificant results.
} 
Table 7 Life satisfaction and job quality: Medium term effects

\begin{tabular}{|c|c|c|c|c|c|}
\hline & $(1)$ & (2) & (3) & (4) & (5) \\
\hline \multicolumn{6}{|c|}{ Employed at year } \\
\hline$t_{1}$ and $t_{2}$ & $\begin{array}{r}1.121 * * * \\
(0.132)\end{array}$ & & & & \\
\hline$t_{1}$ only & $\begin{array}{l}0.009 \\
\quad(0.192)\end{array}$ & & & & \\
\hline$t_{2}$ only & $\begin{array}{r}1.038 * * * \\
(0.162)\end{array}$ & & & & \\
\hline \multicolumn{6}{|c|}{ Low job satisfaction at $t_{1}$ and $t_{2}$} \\
\hline Yes & & $\begin{array}{r}-0.016 \\
(0.441)\end{array}$ & & & \\
\hline No & & $\begin{array}{r}1.265^{* * * *} \\
(0.150)\end{array}$ & & & \\
\hline \multicolumn{6}{|c|}{ Low wage job at $t_{1}$ and $t_{2}$} \\
\hline Yes & & & $\begin{array}{r}0.774 * * * \\
(0.249)\end{array}$ & & \\
\hline No & & & $\begin{array}{r}1.310 * * * \\
(0.168)\end{array}$ & & \\
\hline \multicolumn{6}{|c|}{ Overeducated at $t_{1}$ and $t_{2}$} \\
\hline Yes & & & & $\begin{array}{r}1.084 * * * \\
(0.254)\end{array}$ & \\
\hline No & & & & $\begin{array}{r}1.300 * * * \\
(0.178)\end{array}$ & \\
\hline \multicolumn{6}{|c|}{$\begin{array}{l}\text { Low autonomy in occupational } \\
\text { actions at } t_{1} \text { and } t_{2}\end{array}$} \\
\hline Yes & & & & & $\begin{array}{r}1.025^{* * * *} \\
(0.238)\end{array}$ \\
\hline No & & & & & $\begin{array}{r}1.228^{* * * *} \\
(0.162)\end{array}$ \\
\hline Observations & 4696 & 3742 & 3742 & 3630 & 3742 \\
\hline Pseudo- $R^{2}$ & 0.104 & 0.107 & 0.105 & 0.104 & 0.104 \\
\hline
\end{tabular}

Notes: See Table 5

general, there is only little evidence of adaptation to unemployment within a time span of 5 years and the authors conclude that unemployment has longlasting effects.

So far, our results have shown that within a year of commencing a new job, the quality of this job matters little for overall life satisfaction. For most of our analysis, people employed under adverse working conditions are still better off than those who remain unemployed. Furthermore, differences in the probability to experiencing higher levels of well-being are often not statistically significant between workers in low quality and higher quality jobs.

To see whether job quality only starts to matter at a later stage, we follow individuals over 2 years and only compare satisfaction levels between $t_{0}$ (when everyone was unemployed) and $t_{2}$, but use information regarding employment status and, if applicable, job quality at $t_{1}{ }^{22}$ Results are shown in Table 7. First,

\footnotetext{
${ }^{22}$ Typically, studies analyzing adaptation and habituation effects follow individuals for 4 to 5 years. In our case, the number of observations is too small to extend the analysis beyond 3 years.
} 
we simply control for the employment effect on life satisfaction. As can be seen from column 1, people who have been employed in both years enjoy higher levels of life satisfaction as do people who eventually found employment in $t_{2}$. Those who became unemployed again in $t_{2}$ report similar satisfaction levels than the long-time unemployed.

In columns $2-5$, the underlying sample consists of people who are either employed at $t_{1}$ and $t_{2}$ or remain unemployed in all years. Somewhat restricted by data availability, we select four indicators of job quality and sort people according to the number of years they have been employed under unfavorable conditions. As can be seen from Table 7, results from this approach are very similar to those discussed earlier. For people reporting low job satisfaction levels in two consecutive years there is no significant relationship with life satisfaction. ${ }^{23}$ Regarding other indicators of presumably low quality jobs, results suggest that being employed in low wage jobs, feeling overqualified or having only little occupational autonomy for 2 years is not detrimental to life satisfaction. Hence, within a time span of 2 years, we cannot identify any negative effects of working under less favorable conditions that would attenuate or even outweigh the significant positive effect of commencing a fulltime job after an unemployment spell.

\section{Conclusions}

People taking up a new job out of unemployment are, on average, more satisfied with life than those remaining in unemployment. This has been found in previous studies and has also been confirmed by our results. This paper takes the discussion a bit further, asking what role does the quality of the new job play for life satisfaction. In particular, we are interested in identifying job characteristics that would potentially outweigh the positive effect of finding full-time employment, so that remaining unemployed would be either better or at least no worse for life satisfaction. Previous evidence on this question is based on small case studies and on relatively narrow definitions of job quality. We have tried to overcome these shortcomings by using a large panel dataset with rich information on job- and worker-related characteristics. We analyzed the influence of job quality in the framework of a conditional logit model and controlled for the influence of other factors known to affect life satisfaction. Furthermore, we applied alternative indicators to cover various dimensions of job quality including subjective perceptions of the job, wages and job security, the match between workers' characteristics and job requirements, and features of the new job compared to the pre-unemployment job.

Our results can be summarized as follows: We could not find any single job feature, nor any combination of such features, that make jobs so bad that

\footnotetext{
${ }^{23}$ This result needs to be interpreted with caution since the number of observations is well below 100 for this category. Regarding the alternative specifications of adverse working conditions shown in Table 7, the number of observations is between 300 and 388 .
} 
remaining in unemployment would be the better choice. On the contrary, the bulk of our evidence suggests that even low quality jobs are preferable to unemployment, although they may rise life satisfaction less than high quality jobs. This positive effect continues to persist in the second year of reemployment, and we find no sign of 'negative adaptation'.

Overall, we conclude that subjective measures of job quality are more influential on life satisfaction than objective ones for full-time employees. Our results obtained from the analysis of objective job quality measures suggest that the manifest function of work is fulfilled and hence, life satisfaction is likely to increase. Nevertheless, there are several subjective measures of job quality that can counter the positive effect of re-employment-like low job satisfaction or a perceived worsening in several job dimensions when compared to the previous job. This points to the fact that even if the manifest function of work was assured, its effect on life satisfaction can be cancelled out if the latent function was not fulfilled.

Some important research questions remain. For example, why do unemployed people sometimes reject job offers, even though these jobs may make them more content? One explanation could be that they simply do not anticipate the gain in life satisfaction provided even by a low quality job. Alternatively, it could be a rational strategy to reject the 'bad' job and wait for a better offer which will increase life satisfaction even more. Questions like this need to be addressed within a search and decision model where counterfactual scenarios can be estimated appropriately.

Open Access This article is distributed under the terms of the Creative Commons Attribution Noncommercial License which permits any noncommercial use, distribution, and reproduction in any medium, provided the original author(s) and source are credited.

\section{References}

Booth A, van Ours J (2008) Job satisfaction and family happiness: the part-time work puzzle. Econ J 118:F77-F99

Cabral Vieira J, Menezes A, Gabriel P (2005) Low pay, higher pay and job quality: empirical evidence for Portugal. Appl Econ Lett 12:505-511

Chamberlain G (1980) Analysis of covariance with qualitative data. Rev Econ Stud 47:225-238

Clark A (2005) Your money or your life: changing job quality in OECD countries. Br J Ind Relat 43:377-400

Clark A (2006) Unhappiness and unemployment duration. Appl Econ Q 52:291-308

Clark A, Diener E, Georgellis Y, Lucas R (2008) Lags and leads in life: a test of the baseline hypothesis. Econ J 118:222-243

Clark A, Oswald A (1994) Unhappiness and unemployment. Econ J 104:648-659

D'Addio AC, Eriksson T, Frijters P (2007) An analysis of the determinants of job satisfaction when individuals' baseline satisfaction levels may differ. Appl Econ 39:2413-2423

Das M, van Soest A (1999) A panel data model for subjective information on household income growth. J Econ Behav Organ 40:409-426

Diaz-Serrano L, Cabral Vieira J (2005) Low pay, higher pay and job satisfaction within the European Union: empirical evidence from fourteen countries. IZA discussion paper 1558 
Dockery A (2003) Happiness, life satisfaction and the role of work: evidence from two Australian surveys. In: 5 th path to full employment conference/10th national conference on unemployment. University of Newcastle

Doeringer P, Piore M (1971) Internal labour markets and manpower analysis. Lexington: Heath Lexington

European Commission (2001) Employment in Europe. Office for Official Publications of the European Communities, Luxembourg

Ferrer-i-Carbonell A, Frijters P (2004) How important is methodology for the estimates of the determinants of happiness? Econ J 114:641-659

Frederick S, Loewenstein G (1999) Hedonic adaptation. In: Diener E, Kahnemann D, Schwarz N (eds) Well-being: the foundations of hedonic psychology. Russel Sage Foundation, New York

Fryer D (1986) Employment deprivation and personal agency during unemployment. Soc Behav Int J Appl Soc Psychol 1:3-23

Ganzeboom HBG, Treiman DJ (1996) Internationally comparable measures of occupational status for the 1988 international standard classification of occupations. Soc Sci Res 25:201239

Green F, McIntosh S, Vignoles, A (2002) 'Overeducation' and skills—clarifying the concepts. Manch Sch 70:792-811

Greene WH (2008) Econometric analysis, 6th edn. Pearson Prentice Hall, Upper Saddle River

Haisken-DeNew J, Frick J (2005) Desk top companion to the German Socio-Economic Panel (GSOEP) Version 8.0. Deutsches Institut für Wirtschaftsforschung, Berlin

Haisken-DeNew J, Hahn M (2006) PanelWhiz: a flexible modularized Stata interface for accessing large-scale panel data sets

Hassall E, Muller J, Hassall SL (2004) Working towards ill health? An investigation of psychological well-being in unemployed and employed low-wage earners. Int J Employ Stud 12:73-101

Howell D, Okatenko A (2008) By what measure? A comparison of French and U.S. labor market performance. With new indicators of employment adequacy. SCEPA working paper 2008-02

Jahoda M (1982) Employment and unemployment: a social-psychological analysis. Cambridge University Press, Cambridge

Kassenboehmer S, Haisken-DeNew J (2009) You're fired! The causal negative effect of entry unemployment on life satisfaction. Econ J 119:448-462

Layard R (2004) Good jobs and bad jobs. CEP Discussion Papers 19. London School of Economics and Political Science, Centre for Economic Performance, LSE,

Leana C, Feldmann D (1995) Finding new jobs after a plant closing: antecedents and outcomes of the occurrence and quality of reemployment. Hum Relat 48:1381-1401

Leontaridi R, Sloane P (2001) Measuring the quality of jobs. LoWER Working Papers 7

Liem R (1992) Unemployed workers and their families: social victims or social critics? In: Voydanoff P, Majka L (eds) Families and economic distress. Sage, Beverly Hills

McKee-Ryan FM, Song Z, Wanberg CR, Kinicki A (2005) Psychological and physical well-being during unemployment: a meta-analytic study. J Appl Psychol 90:53-76

O'Brien GE, Feather NT (1990) The relative effects of unemployment and of employment on the affect, work values and personal control of adolescents. J Occup Psychol 63:151-165

Rosen S (1986) The theory of equalizing differences. In: Ashenfelter O, Card D (eds) Handbook of labor economics, vol 1. Elsevier, Amsterdam, pp 641-92

Theodossiou I (1998) The effects of low pay and unemployment on psychological well-being: a logistic regression approach. J Health Econ 17:85-104

Treiman DJ (1977) Occupational prestige in comparative perspective. Academic, New York

Wanberg C (1995) A longitudinal study of the effects of unemployment and quality of reemployment. J Vocat Behav 46:40-54

Winefield A, Tiggemann M, Winefield H, Goldney D (1993) Growing up with unemployment: a longitudinal study of its psychological impact. Routledge, London

Winkelmann L, Winkelmann R (1998) Why are the unemployed so unhappy? Evidence from panel data. Economica 65:1-15 